\title{
APLICATIVO PARA EDUCAÇÃO AMBIENTAL
}

\author{
Luis Augusto Gomes Rocha ${ }^{1}$ \\ Fabiana de Mendonça Cruz ${ }^{2}$ \\ Alcides Lopes Leão ${ }^{3}$
}

\section{RESUMO}

Este trabalho apresenta a criação de um aplicativo na plataforma Android através do sistema App Inventor para que efetue leitura de Códigos QR provenientes de identificações botânicas das espécies arbóreas da "Trilha de Educação Ambiental" inserida na Reserva Biológica de Sooretama. O aplicativo oferece a oportunidade de trabalhar a educação ambiental de forma mais flexível, apresentando os conteúdos de uma maneira mais atraente e lúdica.

PALAVRAS-CHAVE: Educação Ambiental. Aplicativo. QR Code.

\section{APP FOR ENVIRONMENTAL EDUCATION}

\begin{abstract}
This paper describes the creation of an App for Android using "App Inventor" to read QR Codes from arboreal species previously identified from the trail "Trilha de Educação Ambiental" in "Reserva Biológica de Sooretama" - a nature reserve in Brazil. The App offers the opportunity of working on environmental education in a flexible way, presenting knowledge in a much more attractive and ludic approach.

KEYWORDS: Environmental Education; App; QR Code.
\end{abstract}

\section{APLICACIÓN DE EDUCACIÓN AMBIENTAL}

\section{RESUMEN}

Este trabajo presenta la creación de una aplicación para Android a través del sistema App Inventor que lea Códigos $Q R$ presentes en identificaciones botánicas de especies arbóreas de la senda "Trilha de Educação Ambiental" en la "Reserva Biológica de Sooretama" - una reserva natural en Brasil. La aplicación ofrece la oportunidad de trabajar la educación ambiental de manera más flexible, presentando los contenidos de una manera más atractiva y lúdica.

PALABRAS-CLAVE: Educación Ambiental; Aplicación; Código QR.

\footnotetext{
${ }^{1}$ Eng. Florestal, Faculdade de Ciências Agronômicas - UNESP. lagrocha@fca.unesp.br.

2 Bióloga, Universidade Federal do Espirito Santo - UFES. fabianamcruz@gmail.com.

3 Eng. Agônomo, Prof. Dr. Faculdade de Ciências Agronômicas - UNESP. alcideslopesleao@gmail.com.
} 


\section{INTRODUÇÃO}

\section{EDUCAÇÃO AMBIENTAL}

A acomodação do capital é o motivo central das transformações históricopolítico-sociais do mundo ocidental ocorridas nos últimos tempos. É preciso entender que a sociedade em que se vive hoje é, essencialmente, uma sociedade de consumo, contribuindo cada vez mais para um processo de deterioração ambiental em função dos processos de produção.

Marcos históricos de produção, tais como a Revolução Industrial, resultaram em degradações ambientais que afetam a qualidade de vida. Neste contexto, surgiram ações sociais para debater quais as alternativas tecnológicas e os marcos normativos a serem utilizados para minimizar tais passivos ambientais. Uma dessas ações, por exemplo, se deu em 1972, na Conferência das Nações sobre o Ambiente Humano em Estocolmo. Os principais resultados formais do encontro constituíram a Declaração sobre o Ambiente Humano ou Declaração de Estocolmo que expressa a convicção de que tanto as gerações presentes como as futuras tenham reconhecidas como direito fundamental a vida num ambiente sadio e não degradado.

Em resposta às recomendações desta conferência, a UNESCO promoveu em Belgrado um Encontro Internacional em Educação Ambiental, onde criou o Programa Internacional de Educação Ambiental (PIEA). Foram formulados, então, os seguintes princípios orientadores: a Educação Ambiental deve ser continuada, multidisciplinar, integrada às diferenças regionais e voltada para os interesses nacionais.

A partir desta iniciativa, inúmeros tratados e acordos foram realizados, bem como instrumentos legais foram implementados visando nortear as atividades de eduação ambiental. Como em 1999, com a aprovação da Lei no 9.795, que instituiu, no Brasil, a Política Nacional de Educação Ambiental. Outro marco a ser citado é a Declaração de Ahmedabad, de 2007, que debateu internacionalmente e sedimentou que, através da Educação, podem-se compor estilos de vida que apoiem a 
integridade ecológica, a justiça social e econômica, a partir de modos de vida sustentáveis em respeito, assim, a toda forma de vida.

Dentro deste contexto, Reigota (2007) descreve "a Educação Ambiental fundamentada a partir de contribuições da filosofia da ciência, da filosofia política e da filosofia da educação, no contexto de grandes contradições como no Brasil e na América Latina". Devendo a Educação Ambiental procurar estabelecer o que ele diz ser uma "nova aliança" entre a humanidade e a natureza, além de criar uma "nova razão" que não seja a de autodestruição, estimulando a ética nas relações econômicas, políticas e sociais.

Uma ferramenta para auxiliar o processo de educação ambiental, segundo Neiman (2007), é a percepção, pois ela está relacionada à ação de formar mentalmente representações sobre objetos externos a partir dos dados sensoriais, "além disso, cita que a percepção e a própria educação devem estar juntas para possibilitar a expansão da consciência através do envolvimento afetivo das pessoas com a natureza e a cultura local”.

A busca pela compreensão e contato mais direto com os ambientes naturais pode ser considerada como uma das mais fortes tendências da atualidade, uma vez que está cada vez mais evidente à sociedade o grave estágio de degradação de recursos e paisagens. Segundo Milano, "as áreas destinadas à proteção dos diversos ecossistemas necessitam de uso e administração planejados, de modo que sua conservação seja garantida e contemple as finalidades ambientais, científicas, culturais, recreativas e econômicas" (2001, p. 5).

As trilhas têm sido um dos meios mais utilizados para a Interpretação Ambiental, tanto em ambientes naturais, como em ambientes construídos, sendo que atualmente, segundo Vasconcellos (1997), estão muito presentes em programas educativos para uso público, permitindo o desenvolvimento de atividades de educação ambiental tanto em âmbito formal, quanto informal. Assim, de acordo com Jesus \& Ribeiro (2006), as atividades de educação e lazer em ambientes com relevante potencial paisagístico e grande biodiversidade podem se tornar importantes ferramentas para conservação e preservação desses espaços através da educação ambiental. 


\section{EDUCAÇÃO E DESENVOLVIMENTO TECNOLÓGICO}

Os marcos históricos de produção e os desenvolvimentos tecnológicos responsáveis pela degradação ambiental supracitados também resultaram em transformações técnico-científicas que provocam alterações radicais no panorama econômico, social e cultural, acompanhadas de uma reestruturação sem precedentes nos processos de produção e consumo e, consequentemente, nos processos de formação do homem. Essa reestruturação, segundo Lara, "pode ser resumida em uma sociedade da informação, numa sociedade tecnológica ou numa sociedade midiática, onde constata-se o uso cada vez mais frequente das tecnologias digitais em práticas cotidianas, que resultam em mudanças ou incorporações de novas práticas sociais" (2010, p. 2). A sensação de que essas tecnologias digitais disponíveis têm proporcionado uma série de transformações na forma como as pessoas interagem, relacionam-se e como compartilham e recebem informações afeta diretamente na formação do indivíduo.

Lara ainda afirma que "a geração que nasceu na última década do século $X X$ não conheceu um mundo sem telefone celular; é uma geração que cresceu ouvindo falar da internet e utilizando-a para as mais diferentes finalidades, desde jogos online a redes sociais" (2007, p. 4), assim, a ausência dessas tecnologias no ambiente de aprendizado resulta no desinteresse do aluno no processo de aprendizado. Desta forma, o desinteresse sobre o tema, seja ele Educação Ambiental ou qualquer outra disciplina, carece da inserção da tecnologia de forma lúdica, sendo essa necessidade percebida ao decorrer da ultima década.

Nesta perspectiva, partimos do pressuposto de que os movimentos da dita "sociedade da informação" pressionam as instituições - entre elas as instituições educativas - a incorporarem as Tecnologias da Informação e Comunicação (TIC) em suas práticas, assim como acontece em diferentes contextos da vida social. Lara (2007, p. 4) relata que, no atual contexto de "inovações tecnológicas", assumimos a posição de que o desenvolvimento das TIC e sua aplicação nos processos educativos trazem possibilidades de inovação na prática pedagógica e podem contribuir com a qualidade da educação. Entretanto, entende-se que apenas a incorporação das TIC não é suficiente para promover a melhoria desta qualidade. Não se trata somente de uma questão de promoção de acesso aos recursos tecnológicos disponíveis, mas sim de uma questão de avaliar e saber como 
empregar tais recursos nas práticas educativas: é necessário avançar pela questão da qualidade de acesso, que envolve as possibilidades da rede social; indagar como os estudantes podem aprender mais e melhor com os usos das TIC. A partir daí, pensar propostas de uso destas ferramentas que permitam instaurar outros processos de aprendizagem, mais adaptados ao tempo presente e suas necessidades.

Apesar do crescente uso de novos recursos, existem poucos trabalhos na área de Educação Ambiental utilizando Tecnologias da Informação e Comunicação no espaço escolar e em unidades de conservação. Optamos, assim, por pesquisar o uso do telefone celular no processo de ensino e aprendizagem. Segundo Senna, o telefone celular vem atuando como participante assíduo em meio à realidade pedagógica de escolas da rede pública, particular e universitária, já que "representa uma ferramenta que figura intimamente socializada às diferentes práticas sociais, na qual seus usuários demonstram letramentos para o seu uso, como adeptos a consumirem seus avanços e convergências midiáticas” (2010, p. 4). O foco da utilização de aplicativos no telefone celular na educação está centrado nas possibilidade de impacto de seus usos no processo de ensino e aprendizagem, não no acesso propriamente dito, mas na incorporação dessa tecnologia como ferramenta para ensinar e aprender.

Em continuidade, Senna relata que o "telefone celular é voltado à diferentes práticas didáticas tais como a criação e edição de vídeos, de imagens e na pesquisa de temas norteadores, cabendo ao educador ampliar o olhar para a exploração de suas potencializadades para o processo educacional" (2010, p. 5). Diante deste novo panorama, qual poderia ser o alcance do uso de aplicativos no telefone celular para educação e no ensino da Educação Ambiental? Acreditar que as novas tecnologias no ambiente educacional e nas aulas de Educação Ambiental disponibilizam e possibilitam a interação dos alunos com a construção e análise do conhecimento, permitindo que os escolares do ensino fundamental compreendam melhor a vegetação de trilhas bem como sua importância nos processos ecológicos. 


\section{OBJETIVO}

Desenvolver um aplicativo utilizando o APP Inventor com o intuito de propor uma nova ferramenta no processo de ensino-aprendizado junto à Educação Ambiental.

\section{MATERIAIS E MÉTODOS}

O local de estudo se deu na REBIO de Sooretama, localizada entre os municípios de Linhares, Sooretama, Vila Valério e Jaguaré, entre os paralelos $18^{\circ} 55^{\prime}$ e $19^{\circ} 05^{\prime}$ de latitude sul e os meridianos $39^{\circ} 55^{\prime}$ e $40^{\circ} 15^{\prime}$ de longitude oeste. Seu perímetro mede $120 \mathrm{~km}$, perfazendo uma área de 24.250 ha. Segundo Anacleto (1997), a diversidade do clima na região deve-se principalmente à grande extensão de baixadas costeiras e diferenças de relevo. Peixoto e Gentry (1990) classificaram o clima da região como tropical úmido (Am), com precipitação pluviométrica média anual de $1.403 \mathrm{~mm}$ e uma estação seca de maio a setembro, podendo chegar a apenas $33 \mathrm{~mm}$ de chuva nos meses de julho e agosto. A média anual de temperatura é de $23,6{ }^{\circ} \mathrm{C}$, com mínima em julho $\left(15,6{ }^{\circ} \mathrm{C}\right)$ e máxima em fevereiro $\left(27,4^{\circ} \mathrm{C}\right)$. Segundo Instituto Brasileiro de Geografia e Estatística (IBGE) (2004), a vegetação da região norte do estado do Espírito Santo ocorre sob um clima ombrófilo, sem período biologicamente seco durante o ano e, excepcionalmente, com até dois meses de umidade escassa, devendo ser classificada como Floresta Ombrófila Densa. Especificamente em relação ao estande estudado, a vegetação pode ser enquadrada como Floresta Ombrófila Densa das Terras Baixas.

$O$ incentivo da implementação do aplicativo partiu de uma parceria entre a REBIO de Sooretama, Empresa Concremat e Ecovias do Grupo EcoRodovias.

Inicialmente foi realizado o levantamento das espécies (Tabela 1), de maior apelo ambiental na "Trilha de Educação Ambiental" percorrendo seus 2 quilômetros da sua extensão. Exemplares das espécies encontradas foram fotografados (Figura 1), coletados, preparados segundo técnicas usuais de herborização vistas em Bridson (2004), sendo que, para a identificação das espécies encontradas, foram utilizadas bibliografias específicas. A classificação das espécies encontradas em suas respectivas famílias baseou-se em Souza \& Lorenzi (2005). 
da tita Paulista

Figura 1: Marcação e coleta de indivíduos arbóreos
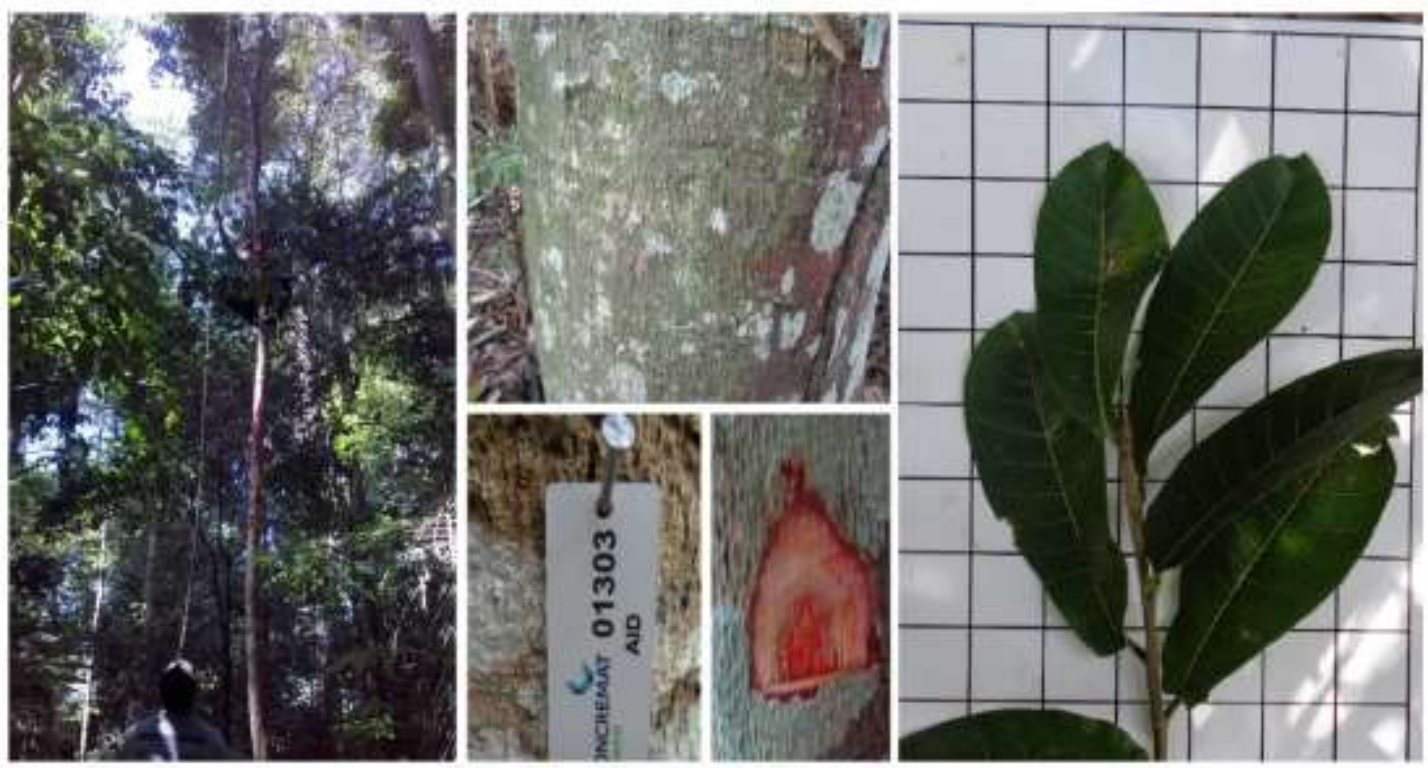

Fonte: Luis Augusto Gomes Rocha, 2015.

Tabela 1: Indivíduos arbóreos identificados

\begin{tabular}{cccc}
\hline Número & Família & Nome Popular & Nome Científico \\
\hline 1301 & BORAGINACEAE & baba-de-boi & Cordia trichoclada DC. \\
1302 & MORACEAE & figueira-preta & Ficus mexiae Standl. \\
1303 & BIXACEAE & urucum & Bixa orellana L. \\
1304 & LECYTIDACEAE & sapucainha & Eschweilera ovata (Cambess.) Mart. ex Miers \\
1305 & SAPOTACEAE & abiu-peludo & Pouteria torta (Mart.) Radlk. \\
1306 & SAPOTACEAE & casca-doce & Pradosia lactescens Vell. \\
1307 & ARECACEAE & palmito-amargoso & Allagoptera caudescens (Mart.) Kuntze \\
1308 & PERACEAE & tabocuva & Pera glabrata (Schott) Poepp. ex Baill. \\
1309 & MORACEAE & inharé & Brosimum lactescens (S.Moore) C.C.Berg \\
1310 & BIGNONIACEAE & cinco-folhas & Sparattosperma leucanthum (Vell.) K. Schum. \\
1311 & MYRTACEAE & grumixama & Eugenia brasiliensis Lam. \\
1312 & FABACEAE & jacarandá-caviúna & Dalbergia nigra (Vell.) Allemão ex Benth. \\
1313 & MORACEAE & folha-de-serra & Sorocea hilarii Gaudich. \\
1314 & LECYTIDACEAE & jequitibá-rosa & Cariniana legalis (Mart.) Kuntze \\
1315 & EUPHORBIACEAE & boleira & Joannesia princeps Vell. \\
1317 & MYRTACEAE & jaboticaba-da-mata & Plinia phitrantha (Kiaersk.) Sobral \\
1318 & MYRTACEAE & ameixa-da-mata & Eugenia candolleana DC. \\
\hline & & &
\end{tabular}




\begin{tabular}{cccc} 
Número & Família & Nome Popular & Nome Científico \\
\hline 1319 & NYCTAGINACEAE & joão-mole & Guapira opposita (Vell.) Reitz \\
1320 & SAPOTACEAE & abiu-peludo & Pouteria torta (Mart.) Radlk. \\
1321 & CARICACEAE & jaracatia & Jacaratia spinosa (Aubl.) A.DC. \\
1322 & SAPINDACEAE & casca-solta & Allophylus petiolulatus Radlk \\
1324 & ANACARDIACEAE & gonçalo-alves & Astronium concinnum Schott \\
1325 & FABACEAE & pau-sangue & Pterocarpus rohrii Vahl \\
1326 & LECYTIDACEAE & sapucainha & Eschweilera ovata (Cambess.) Mart. ex Miers \\
1327 & LECYTHIDACEAE & imbirema-preta & Couratari asterophora Rizzini \\
1328 & FABACEAE & copaíba & Copaifera langsdorffii Desf. \\
1329 & RUTACEAE & arapoca & Neoraputia alba (Nees \& Mart.) Emmerich ex \\
1330 & MALVACEAE & farinha-seca & Kallunki \\
1331 & FABACEAE & angico-rajado & Pseudopiptadenia contorta (DC.) G.P.Lewis \& \\
1333 & MALVACEAE & açoita-cavalo & M.P.Lima \\
1335 & FABACEAE & vinhático & Luehea divaricata Mart. \& Zucc. \\
1336 & LECYTHIDACEAE & imbirema-preta & Plathymenia reticulata Benth. \\
\hline & & Couratari asterophora Rizzini
\end{tabular}

Fonte: Luis Augusto Gomes Rocha, 2015.

Após a coleta, marcação e posterior identificação dos indivíduos arbóreos da trilha, foi compilada uma sequencia de cards baseado no jogo de cartas comercialmente existente chamado Super Trunfo, que são encontrados em diversas formas e sobre assuntos diferentes, inclusive com alguns tópicos de biologia.

O jogo Super Trunfo Árvores Brasileiras, seguindo a classificação proposta por Grando (1995), enquadra-se melhor como um jogo de sorte ou azar, estando os jogos com estas características na preferência da grande maioria das crianças, e por esse motivo o design dos cards seguiu esse modelo.

Assim, fomatando os cards (Figura 2) semelhantes a Canto (2009), montouse uma estrutura que tem como tema central as espécies arbóreas identificadas na trilha, suas características morfológicas e de floração. A escolha pelas características morfológicas se deu porque elas servem de introdução tanto para alunos do ensino fundamental quanto para os de ensino superior em áreas de ciências biológicas e ciências agrárias, uma vez que, nas disciplinas de morfologia 
ou de sistemática esses temas são abordados. Quanto aos períodos de floração, a escolha se deu porque ele é um dos principais apelos visuais que frequentemente são associados às espécies florestais.

Figura 2: Cards para aplicativo

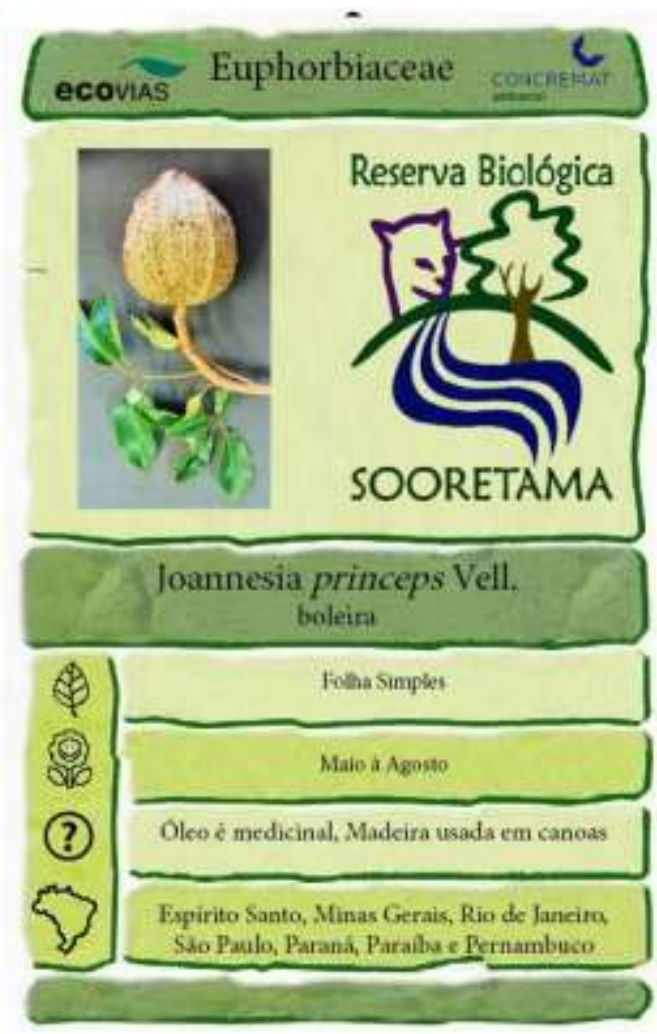

Fonte: Luis Augusto Gomes Rocha, 2015.

Posteriormente, foi criado um "QR Code" de cada um dos indivíduos arbóreos. Os $Q R$ Code, ou códigos $Q R$, podem ser considerados, segundo Santos (2010, p. tal) como a evolução dos códigos de barras comuns, sendo esses códigos em 2 dimenções, representados por matrizes que podem correlacionar uma imagem com um determinado conteúdo. Em seguida, foram compiladas as placas a serem instaladas aos pés de cada indivíduo arbóreo, contendo o nome comum, o científico e um código QR (Figura 3). 
Figura 3: Código QR e Placa
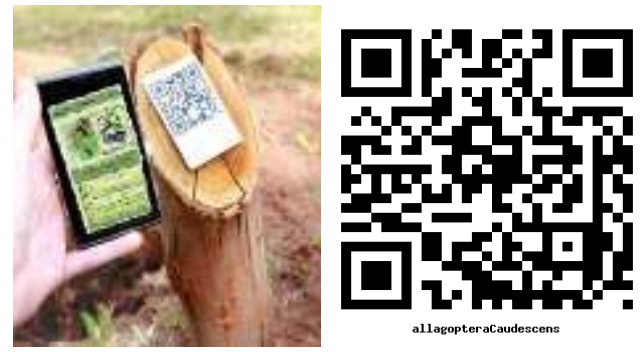

Fonte: Luis Augusto Gomes Rocha, 2015.

Por fim, foi montada uma estrutura do aplicativo utilizando o App Inventor, que, segundo Gomes (2013, p. 4), é uma linguagem de programação visual cujo maior diferencial é permitir que os usuários possam criar aplicativos para dispositivos móveis Android sem necessitar apropriar-se da sintaxe de uma linguagem de programação tradicional. A criação de um aplicativo neste ambiente consiste em uma atividade dividida em dois passos: 1. Criar a interface do usuário para o aplicativo, 2. Definir como o aplicativo se comporta. Estas duas tarefas são realizadas separadamente em duas janelas (Figura 4).

Figura 4: Ferramenta App Inventor: Janela App Inventor Designer

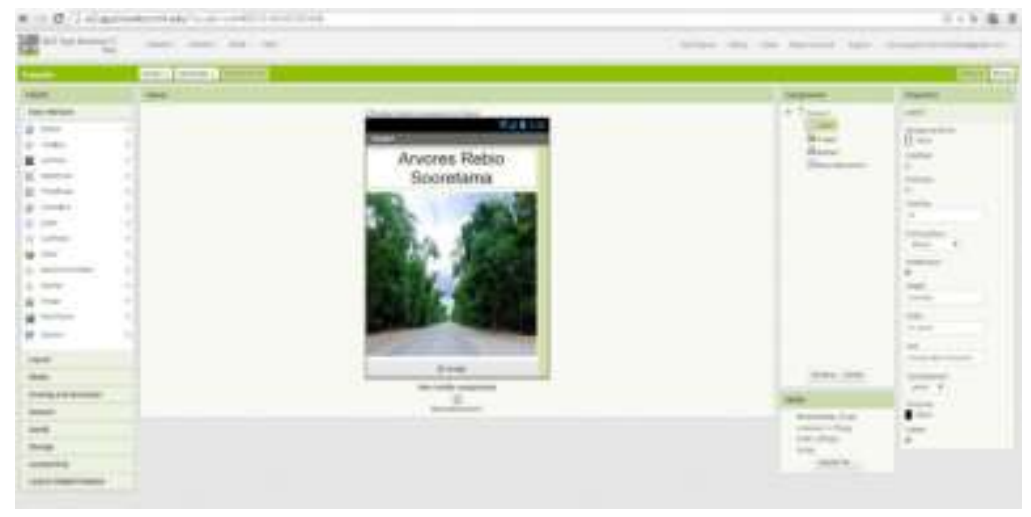

Fonte: Luis Augusto Gomes Rocha, 2015.

Após a fase de programação, uma vez instalado o aplicativo, ele pode ser acessado através do menu principal em um dispositivo móvel, na plataforma Android. Foi criada uma interface inicial do sistema para permitir a ativação da leituro 
do código QR dos indivíduos arbóreos, o que resultará na exibição do "card" de cada árvore da qual a leitura for efetuada.

Uma vez montado o aplicativo, sua sequência de funcionamento se resume a efetuar uma leitura do Código QR existente nas placas instaladas na trilha onde a monitora de educação ambiental vai utilizar as informações que aparecem no celular para sedimentar os conhecimentos a respeitos das características morfológicas das espécies, fixando assim a informação.

\section{CONCLUSÃO}

Todo o procedimento descrito busca o uso do celular como um dispositivo móvel para complementar as ações do educador ambiental frente aos novos desafios educacionais. Procura-se, com isso, uma abertura para o diálogo com os alunos, trazendo maiores possibilidades de interação, comunicação, participação, troca e colaboração entre os envolvidos, viabilizando assim a criação de comunidades de aprendizagem com a integração da tecnologia.

É notório que a introdução destes dispositivos no processo educacional deverá ser acompanhada de mudanças expressivas nos métodos de ensino, sendo necessária a capacitação do monitor ambiental quanto ao contexto das espécies que foram utilizadas na compilação do aplicativo. É importante salientar também que parcerias de instituições públicas com incentivo de empresas privadas podem fomentar pesquisas e desenvolvimentos que auxiliem em projetos em busca da sustentabilidade. 


\section{BIBLIOGRAFIA}

ANACLETO, T. C. Plano de pesquisa para a Reserva Biológica de Sooretama - documento básico. IBAMA, 1997. $48 \mathrm{p}$.

BRIDSON, D. FORMAN, L. 2004. The Herbarium Handbook. Kew, The Royal Botanic Garden.

CANTO, Alisson Reis; ZACARIAS, Marcelo Augusto. Utilização do jogo Super Trunfo Árvores Brasileiras como instrumento facilitador no ensino dos biomas brasileiros. Ciências \& Cognição, v. 14, n. 1, p. 144-153, 2009.

Canto. Super trunfo de Arvores Brasileiras <http://pepsic.bvsalud.org/img/revistas/cc/v14n1/html/a09fig01.html>. Acesso em: 21 Janeiro 2015.

CATAPAN, Araci Hack; FIALHO, FRANCISCO AP. Pedagogia e tecnologia: a comunicação digital no processo pedagógico. Educação, Porto Alegre: PUC/RS, 2003.

DE SOUZA, Janaina Nascimento Simões; BENEVIDES, Rita de Cássia Alves. Educação Ambiental Para o Desenvolvimento Sustentável e o Comprometimento das Universidades/Faculdades do Município do Rio de Janeiro, RJ. II Simpósio de Excelência em Gestão e Tecnologia- SEGeT, 2005

DA CUNHA LARA, Rafael; MAGALHÃES, Juliane Nacari. Entre Impressões De Estudantes E Professores: Um Estudo Sobre O Uso Das Tic Na Formação Inicial de Professores Nas Universidades Públicas Em Santa Catarina, 2007.

DOS SANTOS, Izabela AM et al. Utilizaç ao de Códigos QR em Dispositivos Móveis para Cadastro e Compartilhamento Automático de Informações Pessoais. 2010.

GOMES, T.; MELO, J. O Pensamento Computacional no Ensino Médio: Uma Abordagem Blended-Learning. In: Anais do XXI Workshop sobre Educação em Computação-XXXIII Congresso da Sociedade Brasileira de Computação. Maceió, AL-Brasil. 2013.

JESUS, J.S.; RIBEIRO, E.M.S. Diagnóstico e proposta de implementação de trilha no Parque Metropolitano Armando de Holanda Cavalcanti, Cabo de Santo Agostinho, PE. In: Anais do Io Congresso Nacional de Planejamento e Manejo de Trilhas. Rio de Janeiro: Infotrilhas, 2006.

Reigota,Marcos.Meio ambiente e representação social.7ª ed.São Paulo:Cortez,2007.

LARA, Rafael Cunha; QUARTIERO, Elisa Maria. Educação para uma geração pós-internet: olhares a partir da formação inicial de professores. In:Congresso Iberoamericano de Informática Educativa, Santiago, Chile. 2010.

SME, Dianne Sena; BURGOS, Taciana. O computador e o telefone celular no processo ensinoaprendizagem da educação física escolar, 2010.

NEIMAN, Z. A Educação Ambiental através do contato dirigido com a natureza. Doutorado, Psicologia Experimental, USP, 2007

MILANO, M. S. Conceitos e princípios gerais de ecologia e conservação. In: FUNDAÇÃO O BOTICÁRIO DE PROTEÇÃO À NATUREZA (Ed.). Curso de administração e manejo em Unidades de Conservação. Curitiba: FBPN, 2001. p. 1-55. 
da Alta Paulista

PEIXOTO, A. L.; GENTRY, A. Diversidade e composição florística de mata de tabuleiro na Reserva de Linhares (Espírito Santo, Brasil). Revista Brasileira de Botânica v. 13, p. 19 - 25. 1990.

SOUZA, V.C.; LORENZI, H. 2005. Botânica Sistemática, Guia ilustrado para identificação das famílias de angiospermas da flora brasileira, baseado em APG II. Instituto Plantarum, Nova Odessa.

GODOI, T.A.de F.; OLIVEIRA, H. P. M. de; GODOGNOTO, L; Tabela periódica - Um super trunfo para alunos do ensino fundamental e médio. Química nova na escola, vol. 32 ํo1, 2010. pág 22 25. 